\title{
HERRAMIENTA DEL PUEBLO: EL LIBRO EN LA UNIDAD POPULAR ${ }^{1}$
}

\author{
Patricio A. Bascuñán ${ }^{2}$
}

\section{Resumen/Abstract}

El presente artículo trata sobre el libro y su relevancia dentro del contexto de la Unidad Popular. Atiende principalmente a las colecciones populares y libros de bolsillo que circularon durante el periodo. La exposición se ordena en tres partes. Primero se procede a caracterizar el campo de la cultura durante la Unidad Popular, con el fin de reconocer la función -y necesidad- del libro en el periodo. Luego se analizan las estrategias y prácticas que empleadas en la conformación de nuevos públicos lectores. Por último, se realiza un estudio visual de las portadas del momento. El artículo tiene como objetivo contribuir al conocimiento e información que se dispone sobre la industria editorial de aquel entonces. Para esto se pretende llenar algunos vacíos, en particular sobre Libros Cormorán y la edición universitaria. También se propone estrechar dos áreas de interés: el campo letrado y el de la gráfica.

Palabras clave: Unidad Popular, industria editorial, libros de bolsillo, cultura gráfica

This article is about the book and its relevance in the context of the goverment of Salvador Allende. Mainly attends to the popular collections and paperbacks that circulated during the period. The exhibition is arranged in three parts. First, the field of culture during govermet of the Unidad Popular will be characterized, in order to recognize the function - and necessity-of the book in the period. Then the strategies and practices used in the formation of new reading audiences will be analyzed. Finally, a visual study of the covers of the moment will be carried out. The article aims to contribute to the knowledge and information available about the editorial industry at that time. For this, it is intended to fill some gaps, in particular about Libros Cormorán and the university edition. It is also proposed to narrow down two areas of interest: the literary and the graphic fields.

Keywords: Unidad Popular, editorial Industry, paperbacks, graphic culture

\footnotetext{
${ }^{1}$ Este trabajo originalmente fue presentado en el Seminario Internacional “A 50 años del triunfo de la Unidad Popular", con sede en la Ciudad de México, en el mes de septiembre del 2020. Para el encuentro desarrollé un pequeño documental que se encuentra disponible en https://www.youtube.com/watch?v=qbljH_kV1c4 Para la presente versión se ha sumado alguna información acerca de la edición universitaria y se han desarrollado con mayor profundidad algunas ideas sobre la visualidad.

${ }^{2}$ Chileno, Universidad Diego Portales. E-mail: patopatriciob@gmail.com
} 


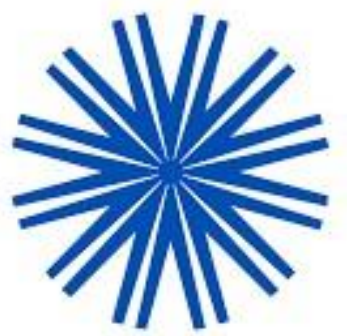

En el presente artículo me referiré al libro y su relevancia dentro del proceso de la vía chilena al socialismo. En particular me interesan las colecciones populares y libros de bolsillo que circularon durante el periodo. Aquellos que se imprimían en tirajes masivos, se encuadernaban en rústica, empleaban portadas muy llamativas y vendían a bajo costo por dentro y fuera de librerías. Objetos vulgares, sencillos. No obstante, tremendamente relevantes y significativos.

Mi objetivo es generar una contribución en torno al conocimiento e información que se dispone del campo editorial del periodo. Reconozco un terreno previamente allanado, del cual se disponen excelentes investigaciones. Sin embargo, las referencias del periodo suelen centrarse en el caso Quimantú, dejando de lado otras experiencias tremendamente relevantes ${ }^{3}$. Quisiera aportar llenando algunos vacíos existentes, en particular sobre Libros Cormorán y la edición universitaria. También me propongo estrechar dos áreas de interés: el campo letrado y el de la gráfica, ambos estudiados desde distintas disciplinas sin dialogar debidamente. Junto a la exposición de mis propias indagaciones, quisiera sintetizar lo que ofrece la bibliografía existente.

Para mi investigación he recurrido a varias lecturas, sin embargo, gran parte del material que nutre este trabajo se debe a derivas callejeras, por fuera de las morrocotudas instalaciones de la Biblioteca. Exceptuando algunas rarezas que he adquirido por internet, todo mi archivo lo he constituido deambulando por la urbe, en ferias libres y barrios populares, junto a cachureos y puestos de verdura.

Esto me permite aseverar: los libros son un elemento constitutivo de la cultura material. Como tales, su estudio y abordaje puede desplazarse por fuera del contenido. No son mera textualidad. Tienen cuerpo y son varios los hitos en sus vidas que los marcan de huellas y significan. Es por esto que mis análisis, en sintonía con los estudios materialistas del libro y la edición ${ }^{4}$, consideran tanto lo relativo al contenido de las obras como las prácticas “materiales” vinculadas al diseño, producción, circulación y recepción de la

\footnotetext{
${ }^{3}$ Pienso en los trabajos sobre Quimantú de Soléne Bergot (2004) y la reciente publicación de Molina, Facuse y Yáñez (2018); el esfuerzo de César Albornoz (2005) de comprender en relación con lo acaecido en los mundos del libro, revistas, música, cine y la cultura en general; por supuesto considero como base de mi trabajo la Historia del Libro en Chile de Subercaseaux (1993).

${ }^{4}$ Acerca del "giro material”en los estudios del libro véase Saferstein, Ezequiel (2013).
} 
cultura impresa. Prácticas que puestas en relación con procesos sociales más amplios, permiten reconstruir las maneras determinadas en que se desarrollaba la edición y la lectura.

Mi exposición se ordena en tres partes. Comenzaré por caracterizar el campo de la cultura durante la Unidad Popular, con el fin de reconocer la función -y necesidad- del libro en el periodo. Cabe mencionar que, por un tema de extensión, por cultura me referiré exclusivamente a la producción artística e intelectual. Luego analizaré las estrategias y prácticas que se emplearon en la conformación de nuevos públicos lectores. Por último, realizaré un estudio visual de las portadas.

\section{Vulgares e ilustradas}

Tal como menciona Carolina Espinoza, "Para la Unidad Popular, los ciudadanos y ciudadanas debían tener acceso a todos los bienes de la civilización. No solo los materiales sino también los que alimentaban el espíritu. Solo así, con una expansión real de la cultura se promulgaría la igualdad de derechos y deberes de las personas"

Este proyecto cultural no está ajeno de tensiones internas. Quisiera ahondar en el choque entre los valores de una cultura mesocrática, de matriz ilustrada y anti oligárquica, y sus mediaciones con la cultura de masas, atravesada por una fuerte impronta norteamericana.

Con cultura mesocrática refiero a las formas y expresiones propias de ciertos sectores de la clase media, que adquieren un lugar protagónico en la escena pública desde comienzos del siglo XX, junto a la crisis del modelo oligárquico y el desplome de su visión elitista de la cultura. Su desarrollo tiene como base una economía hacia adentro, la industrialización nacional, la ampliación de la cobertura educacional y el Estado de Bienestar, donde los sectores medios son operarios y/o directos beneficiarios. En su ideario se encuentran las aspiraciones al desarrollo en el más amplio sentido y la expansión del ejercicio de la ciudadanía ${ }^{6}$.

\footnotetext{
${ }^{5}$ Espinoza, Carolina (dir.). El tren popular de la cultura [DVD]. Chile / España, Sociedad Sonora, 2015.

${ }^{6}$ Acerca del desarrollo de la clase media en Chile véase Candina, Azun (ed.) (2013). En particular me ha sido de utilidad el ensayo de Patrick Barr-Melej, "Vistas mesocráticas: apuntes sobre el estudio de las capas medias en América Latina".
} 
La cultura mesocrática está atravesada por una matriz ilustrada de pensamiento que se fundamenta en la cosmovisión científica y la herencia del humanismo. Privilegia la palabra escrita y el conocimiento acumulado. Supone un deber ser de la cultura, en oposición a la frivolidad del mundo del espectáculo. ${ }^{7}$

Las raíces del marxismo y la cultura de izquierdas se vinculan con esta tradición. Pese al ímpetu de superar los valores burgueses y los fundamentos del capitalismo, traza una continuidad con las bases enciclopédicas y la aspiración a la universalidad del pensamiento liberal, del cual bebe la cultura mesocrática. Esto es patente en las apelaciones al trabajador, en tanto sujeto universal y ejemplar, libre de la contaminación de la cultura de masas ${ }^{8}$. Al respecto, la figura del obrero ilustrado es paradigmática.

Como menciona César Albornoz (2005), "la propuesta cultural de la Unidad Popular no era liviana: era militante, combativa, severa." (151). Por lo mismo, todas las influencias hippies y contraculturales provenientes de las metrópolis eran sospechosas. Así mismo, la experimentación artística será cuestionada en pos de una cultura popular, de fácil entendimiento. Esta situación motiva, por ejemplo, a un grupo de escritores, entre los que se encuentra Enrique Lihn, Jorge Edwards, Alfonso Calderón, entre a otros ${ }^{9}$, a denunciar el "peligro de la ortodoxia en la creación y la correspondiente limitación de la misma" (152).

Sin embargo, pese a las reticencias de algunos, durante los 1000 días de la Unidad Popular se gesta una tremenda modernización cultural. El compromiso político logra relacionarse con la experimentación artística. Sin perder el horizonte de la lucha de clases y del nuevo amanecer, los más modernos exponentes globales son asimilados -y transculturados-en todas las ramas de la creación.

\footnotetext{
${ }^{7}$ Esta idea la desarrolla Subercaseaux, Bernardo (1993).

${ }^{8}$ Acerca de las matrices culturales y la representación de la clase trabajadora en la prensa popular en Chile véase el primer capítulo de Guillermo Sunkel (1985). El autor reconoce una fuerte presencia de una matriz ilustrada en la prensa popular donde se apela al trabajador, en tanto figura universal, como protagonista de la historia. Es relevante la figura épica y heroica que se construye en torno suyo, que supone a un sujeto libre de la contaminación de la cultura de masas.

${ }^{9}$ Albornoz hace referencia del texto "Por la creación de una cultura popular nacional" publicado en Cormorán No 8, diciembre de 1970.
} 
Para esto se torna clave la superación de los límites de la alta cultura. En pos de la conquista del sentido común se hace necesario -e inevitable- zambullirse en la cultura de masas. Hablamos de un mundo

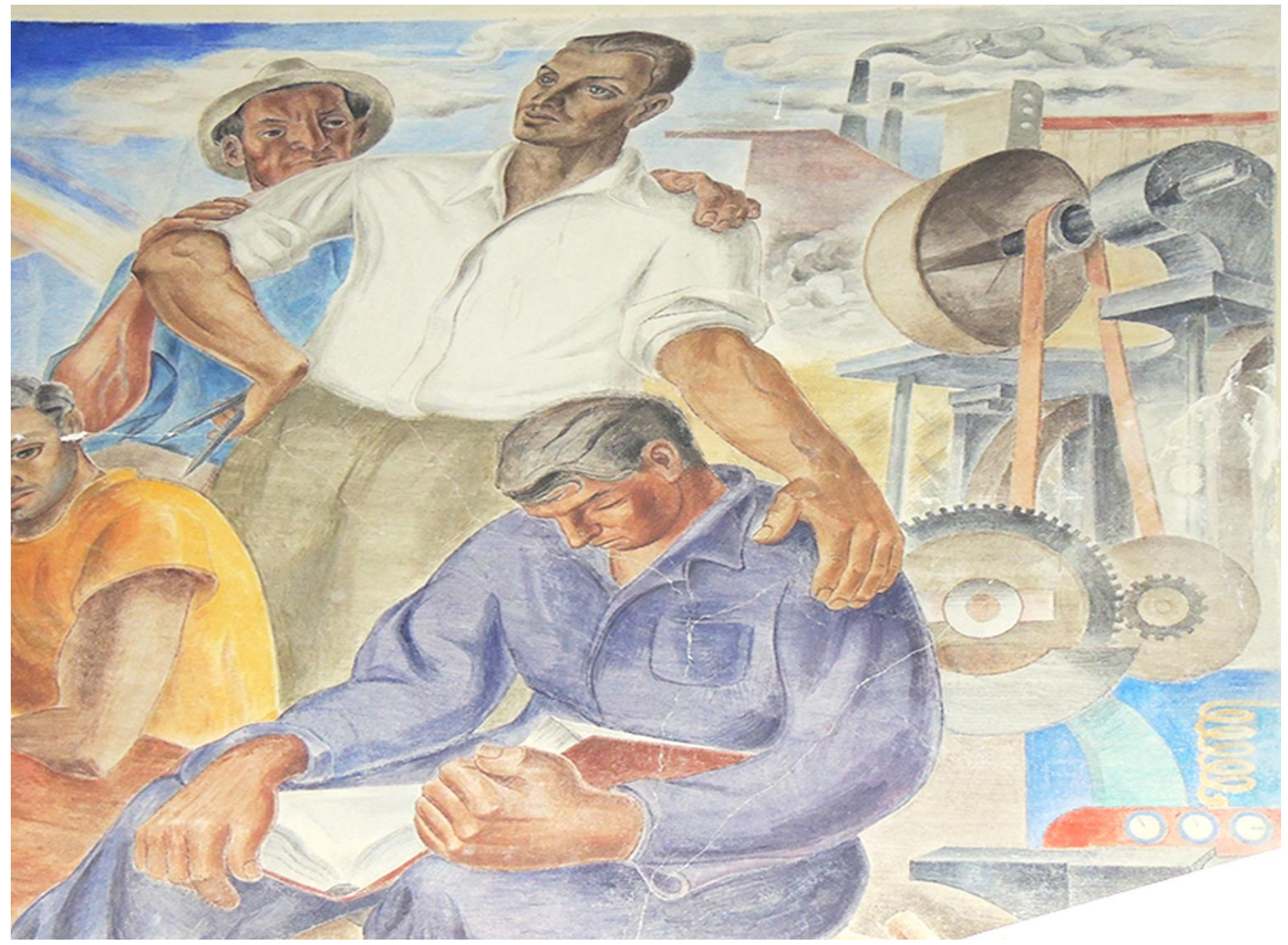

Figura 1

Extracto del mural Historia de Concepción (1943) de Gregorio de la Fuente, realizado en la Estación de Ferrocarriles de Concepción. La fotografía fue extraída de Vera, Rodrigo (2020). Modernidad, espacio urbano y representación de mundo, p.91. Santiago: Lom Ediciones. Llama la atención la asociación de la industria, la imagen paternal del capataz y la figura del obrero ilustrado, en primer plano. Sugiere que el progreso de la nación precisa tanto de un cuerpo social disciplinado, fuerte y saludable como instruido.

complejo y diverso, nutrido a lo largo del siglo XX por las industrias culturales del cine, prensa, magazines, radio y, posteriormente, televisión, masificada en Chile desde el mundial del 62. Se trata de medios que fomentarán una cultura masiva y global, que representarán la vida de los nuevos sujetos urbanos y sus formas de socialización y consumo ${ }^{10}$.

\footnotetext{
${ }^{10}$ Acerca del desarrollo de la cultura de masas en Chile véase Ossandon y Santa Cruz (2005).
} 
La mayor dificultad de conquistar la cultura de masas radica en un tema estructural. Existía, tal como en la actualidad, un control de los medios por parte de capitalistas transnacionales. Esto será denunciado, entre otras personas, por el sociólogo Armand Mattelart (1972), quien asevera que Estados Unidos domina el 65\% del flujo mundial de mensajes y goza ventajas para instalar sus valores "universales" de corte imperialista. A esta realidad habría que sumarle la existencia de una prensa monopólica local, controlada por una burguesía reaccionaria, fiel a los mandatos del imperialismo.

En este contexto se le fija a la lectura un rol muy relevante. El libro será considerado herramienta del pueblo (figura 2), en la medida que brinda insumos a las grandes mayorías para formarse una imagen adecuada del mundo. Una labor de concientización, fundamental en la formación de una nueva moral y de la conducta ejemplar del "hombre nuevo", entrecomillas.

En la época son reconocibles diversos discursos e idearios, no ajenos de tensiones, que forjan una necesidad percibida en torno al libro y la lectura. Yo distingo al menos tres:

1) en relación con la mentada matriz ilustrada de pensamiento, el libro cumple un rol protagónico, entendido como bien cultural superior, en oposición a otros medios como las revistas y la televisión (Subercaseaux, 1993).

2) recogiendo algunos Conceptos elementales del materialismo histórico de Marta Harnecker (1969), autora encargada de la colección Cuadernos de educación popular de Quimantú, el libro se podía entender como una herramienta de la lucha de clases, tanto como vehículo de pensamiento para enfrentar la "acción deformadora" de la ideología burguesa, como bien económico que, junto a bibliotecas, escuelas, ateneos, etcétera, daba forma a condiciones materiales objetivas que servían de base para la toma de conciencia;

3) Asumiendo las lógicas de la cultura de masas el libro se considera un objeto vulgar y cotidiano, que tiene que ser atractivo y estimulante.

A continuación revisaremos como las distintas maneras de percibir al libro se traducen en prácticas concretas. 


\section{Revolución del libro}

Desde comienzos de los años cincuenta hasta fines de los sesenta la industria editorial chilena padece una decadencia sostenida. Nada quedaba de aquel apogeo de las décadas del treinta y cuarenta cuando, por ejemplo, una editorial como Ercilla llegó a publicar un título diario. La época de oro de la industria chilena ${ }^{11}$ se acaba una vez que la industria española vuelve a levantarse, tras recuperarse de los embates de la Guerra Civil y la Segunda Guerra. Por diversos motivos, como la ausencia de apoyo estatal, la precariedad de la industria y sus elevados costos de producción, se hace insostenible la competencia en un mercado latinoamericano. Como menciona Bernardo Subercaseaux (1993), en este periodo el libro queda fuera de la industria cultural moderna. Nuevos medios como la radio y las revistas se apropian del creciente mercado de la entretención.

Sin embargo, a finales de los sesenta se gestan varios esfuerzos para revertir la situación. En el año 1967 la Editorial Universitaria, enarbolando las banderas del movimiento estudiantil que conducirían a la Reforma del 68, publica la serie de bolsillo Libros Cormorán. Movilizando un rubro por entonces alicaído, Universitaria se lanzó a la disputa de la cultura de masas con un catálogo con tremenda amplitud temática e impreso en ediciones económicas. Fue una serie que hasta 1973, año que circuló con regularidad, contaba con más de 160 títulos y 15 colecciones diferentes, que abarcaban temáticas bastante diversas: literatura hispanoamericana, nueva literatura nacional, autores clásicos, biografías, ciencia, filosofía, ciencias sociales, historia nacional, historia latinoamericana, teatro, entre otras. Desde libros para estudiantes escolares hasta manuales y monografías para disciplinas específicas, fue una serie que apuntaba a un público masivo y heterogéneo.

Tal como se menciona en un catálogo de 1973, Libros Cormorán fue "uno de los pasos que iniciaron en Chile la marcha hacia [...] la revolución del libro". (Catálogo Cormorán 1973) Esto refiere al proceso de adaptación del libro a la moderna cultura de masas, convirtiéndose en uno de los grandes medios de información paralelamente a la prensa, el cine, la radio y la televisión. Un proceso que se iniciaría, según

\footnotetext{
${ }^{11}$ Acerca de la época de oro de la industria editorial chilena véase a Subercaseaux (2008).
} 
Robert Escarpit (1965), en 1935 con la aparición del paperback -o libro de bolsillo- de Penguin Books, donde el libro pasa a ser concebido como "vehículo, no monumento" (p. 12). En Latinoamérica varios proyectos editoriales acusarán recibo de estas transformaciones antes que Universitaria, como son el caso de EUDEBA, Sudamericana y CEAL en Argentina, Fondo de Cultura en México, Casa de las Américas en Cuba y Populibros en Perú. Hablamos de proyectos con un horizonte masivo y popular, que facilitarán

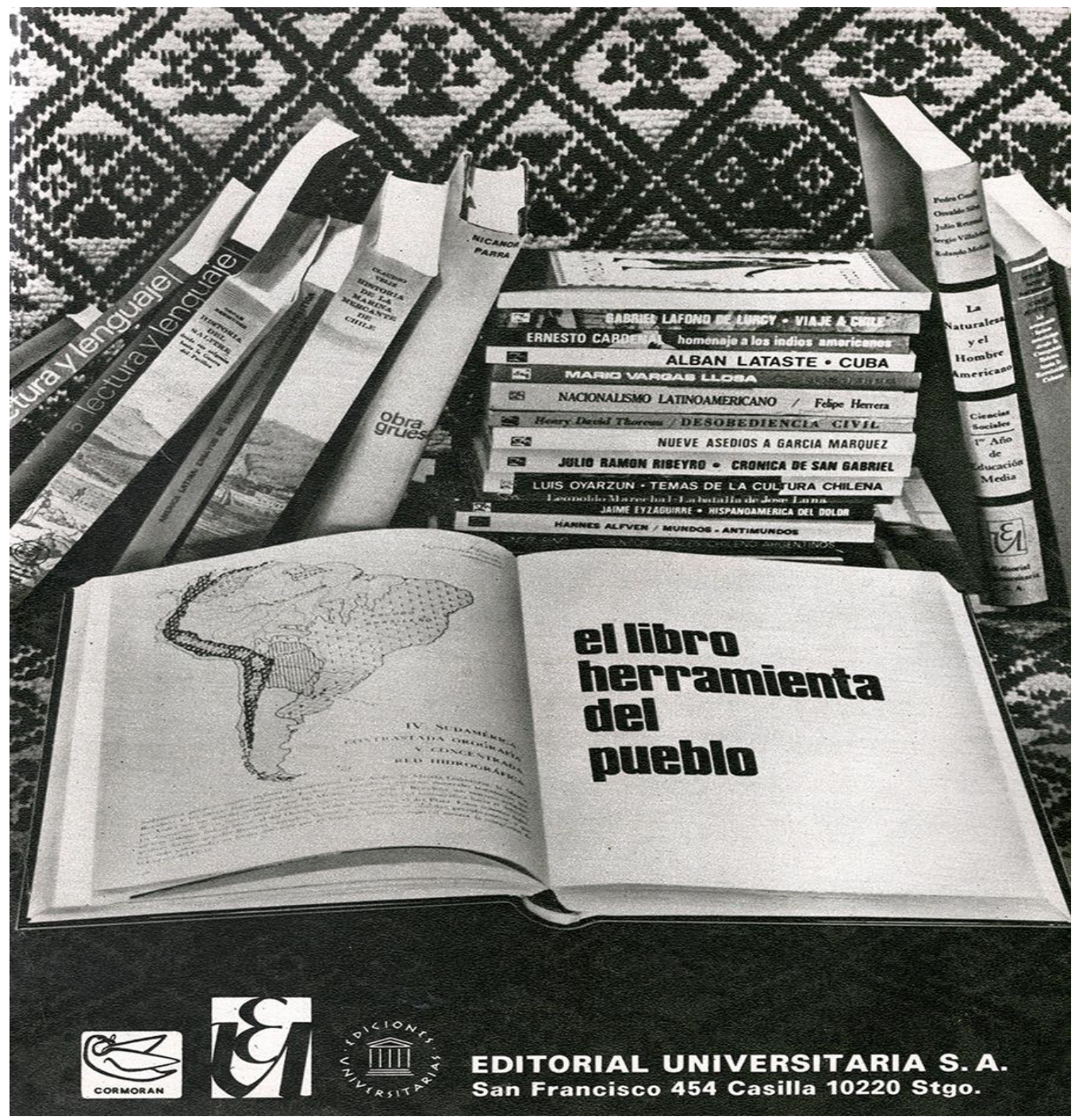

Figura 2

Revista Ahora, 1971. Colección personal de Carlos Montes de Oca y Jorge Montealegre. Extraida de http://www.disenonacional.cl/

Son significativas las alusiones de lo "latinoamericano" - el textil del fondo, el mapa de América del Sur-, a su vez la selección de títulos ligadas al boom y de historia y geografía local. Según Subercaseaux (1984, p.48), esta publicidad da cuenta de la "Influencia del

la expansión de los públicos lectores - de la mano de la ampliación de la cobertura educacional y el 
crecimiento de los mercados internos- y permitirán, entre otras cosas, el desarrollo del boom latinoamericano, un fenómeno de la sociedad de consumo, como sugiere Ángel Rama (1984).
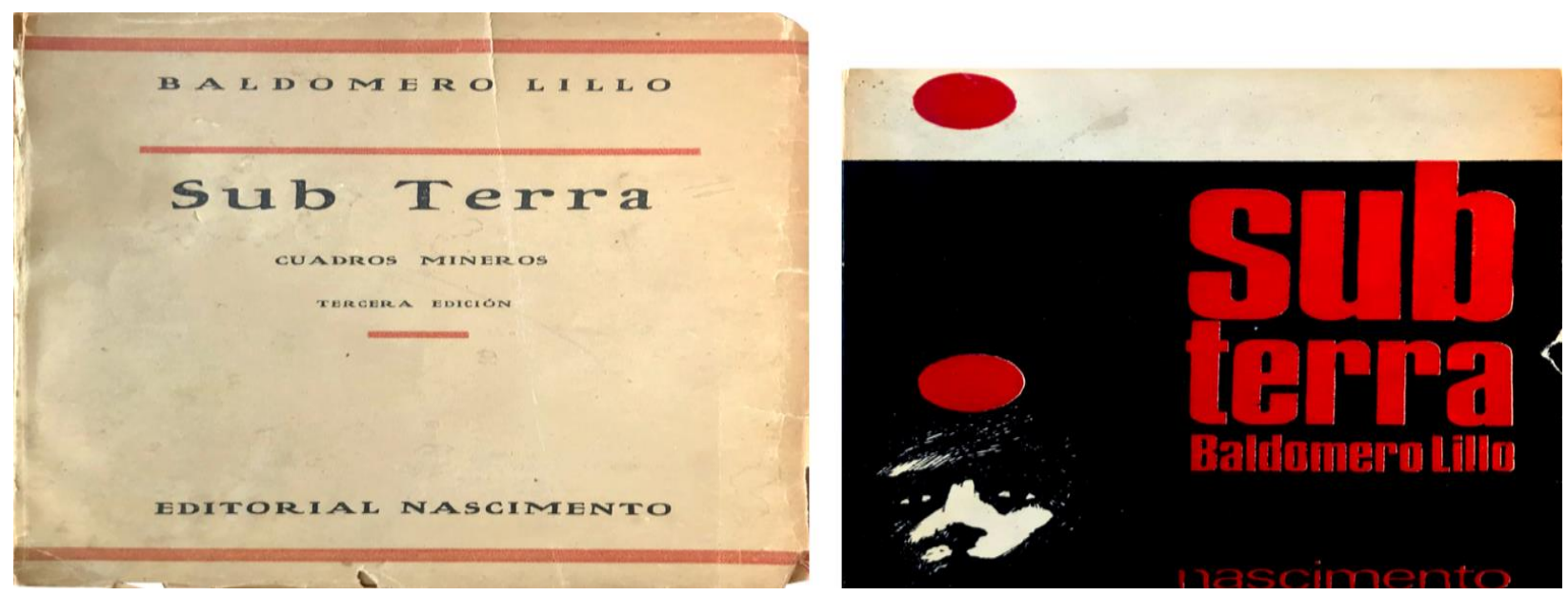

Figura 3

A la izquierda el diseño de portada de la tercera edición (1943), el cual no presenta mayores variaciones desde su primera edición de Nascimento de 1931 y que se mantiene por varias reediciones. A la derecha la decimocuarta edición de 1970, con un diseño de Hernán Vidal (Hervi). Además del notorio cambio en la visualidad de la portada,

Localmente el impulso de Universitaria será seguido por otros proyectos universitarios como las ediciones de la Católica de Valparaíso ${ }^{12}$ o la UTE, que abandonarán el carácter instrumental y endogámico de las ediciones universitarias en pos de ampliar los públicos lectores. Son iniciativas que acogerán los aspectos ideológicos de la Reforma Universitaria, entiéndase las aspiraciones por una democratización del conocimiento - en oposición a la figura de la universidad vista como enclave, ajena a las necesidades de la nación- y el ímpetu de fortalecer un pensamiento crítico e integral -que superase el carácter pragmático y profesionalizante de los espacios académicos. Todo esto en pos de la transformación de la sociedad en su conjunto ${ }^{13}$.

Es importante resaltar que el triunfo electoral de Salvador Allende será un catalizador de un proceso de modernización de la industria en curso. Lo acontecido dentro del campo de la edición universitaria será la

\footnotetext{
${ }^{12}$ Un excelente trabajo acerca de las Ediciones de la Universidad de Valparaíso es el que realizó Huirimilla-Thiznau, A., ArrosAravena, H. y Molina, R. (2019).

${ }^{13}$ Acerca de la Reforma Universitaria en Chile véase Casali (2011) o Garretón (2011).
} 
antesala de otros proyectos significativos y de gran envergadura, como la Biblioteca Popular Nascimento y la Empresa Editora Nacional Quimantú.

Para 1970 es constatable un giro en las prácticas y estrategias de Editorial Nascimento, la empresa fundada por Georges Nascimento en 1917, reconocido por su labor en difundir las letras chilenas a lo largo del siglo XX, piénsese en sus apuestas por Gabriela Mistral, Eduardo Barrios, Teresa Wilms Montt, Manuel Rojas o un joven Neruda. Dentro del contexto de la Unidad Popular se reeditarán varios títulos del catálogo en formatos económicos, con portadas llamativas que le darán una nueva fisonomía a las obras más célebres de la editorial (figura 3). Ya para 1971 se creará la Biblioteca Popular Nascimento, dirigida por Hernán Loyola hasta 1973. Una colección de libros económicos destinada a satisfacer las demandas de un público escolar y general. En pos de abaratar costos se apostará por la reedición de autores nacionales o extranjeros cuyos derechos estuviesen adquiridos o caducados. Uno de los elementos más memorables de esta colección son los excelentes prólogos que introducen las obras, escritos con una clara vocación pedagógica, realizados en gran parte por reconocidos académicos pertenecientes al Departamento de Español de la Universidad de Chile. ${ }^{14}$

La Empresa Editora Nacional Quimantú es, probablemente, el proyecto de mediación cultural más importante de la Unidad Popular y, sin lugar a duda, la gesta más ambiciosa en la historia del libro en Chile. Nace en febrero de 1971, tras la adquisición por parte del Estado de los activos de Zig-Zag, entre ellos toda su maquinaria. Al igual que el resto de las editoriales mencionadas, apostó de lleno por el libro de bolsillo ${ }^{15}$.

Es importante enfatizar que no se trata de un mero cambio de formato. Menciona César Albornoz (2005): "El libro de bolsillo, soporte principal de esta nueva cultura editorial masiva y popular, se transformaba en uno de los principales símbolos del acceso generalizado a la cultura formulado e incentivado por la Unidad Popular.”(p. 156) Se asocia con una cambio radical en la maneras de concebir al libro y la cultura,

\footnotetext{
${ }^{14}$ Aún no se ha realizado un debido estudio de la Biblioteca Popular Nascimento. Lamentablemente la investigación de Felipe Reyes (2013), dedicada a la vida y obra de Georges Nascimento, ofrece bastante escueta la información al respecto. Lo que aquí expongo es fruto de una relación epistolar que he sostenido con Hernán Loyola.

${ }^{15}$ Me abstendré de hablar más de Quimantú ya que existen muy buenos trabajos al respecto. Tal como he mencionado más arriba, sugiero la lectura de Bergot (2004), Subercaseaux (1993) o el libro editado por Molina (2018). Es importante mencionar que Zig-Zag siguió operando como editorial durante el periodo. La empresa realizó varias co-ediciones con Editorial Rodas en España, donde dispuso de los títulos de su catálogo.
} 
donde se hace preciso "combatir las librerías cerradas a la hora que se sale del trabajo, los altos precios de los libros, los bajos tirajes, el poco conocimiento de los valores literarios nacionales y -lo más esencial- el concepto del libro como mercancía" (Ídem).

Es muy significativa la reducción de los formatos en el periodo. Los libros pierden su monumentalidad. Se abandona el formato de $15 \mathrm{x} 21,5 \mathrm{~cm}$., recurrente hasta mediados de los sesenta, y se opta producir no
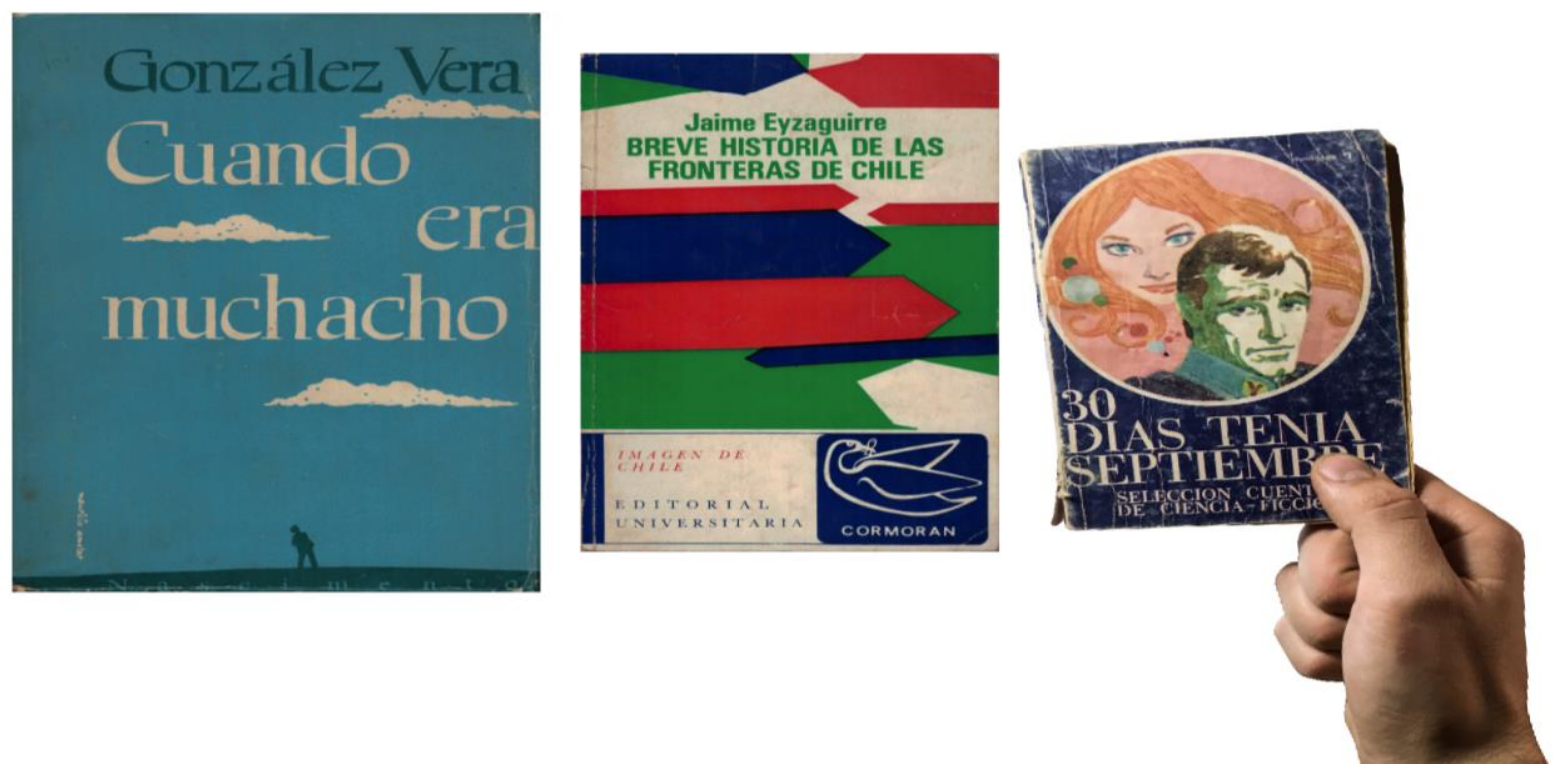

Figura 4

Imágenes a escala de libros del periodo. A la izquierda Cuando era muchacho (1964) de José Santos Gonzalez Vera, Editorial Nascimento, con portada de Mauricio Amster. 21,5 x $15 \mathrm{~cm}$.

Al centro Breve historia de las fronteras de Chile (1967) de Jaime Eyzaguirre, Editorial Universitaria, proyectado por Mauricio Amster, 18 x $12 \mathrm{~cm}$. A la derecha 30 días tenía septiembre (1973), VV.AA.,

más grandes de 12x18cm. Los Minilibros de Quimantú, de 10x14cm., son el caso más representativo. Realmente caben en el bolsillo. (Figura 4). Es muy significativa la reducción de los formatos en el periodo.

Los tirajes de los libros aumentarán explosivamente. Se alcanza un nivel de masividad inédita en el país. Antes de 1971 los tirajes en Chile eran de un promedio de 2000 ejemplares, y raramente sobrepasaban los 
5000. Esto cambia radicalmente con Quimantú. Los tirajes en ciertas colecciones no bajan 30.000, llegando a las 80.000 copias algunos casos. Según Solène Bergot (2004), "la producción total de las colecciones de Quimantú entre septiembre de 1971 y septiembre de 1973 puede ser evaluada, en casi doce millones de ejemplares". (p.22) De estos un 70\% fue vendido, menciona Bergot. Cifras significativas para un país de no más de diez millones de habitantes.

Para llegar a un público mayor fue clave ampliar los canales de distribución. Eran pocas las librerías y casi todas se concentraban en el centro y los barrios acomodados de la capital. Además, las bibliotecas de escuelas elementales y medias eran precarias y había una ausencia de bibliotecas públicas en zonas aisladas. Esto impulsará a la apuesta de vías no tradicionales, como los servicios de bibliobuses o, tal como lo hizo Quimantú, la generación de convenios con organizaciones sindicales y la formación de circuitos de distribución en quioscos, de los cuales se estima que había de 8.000 a 9.000 a lo largo del país. Es un tema a la vez simbólico, que tiene que ver con la cercanía del quiosco, en oposición a la solemnidad de las librerías. Fuese como fuese, los libros encontraron nuevos lectores. Timbres y marcas de lectura lo atestiguan.

En términos de contenido existe una amplia bibliodiversidad. En pos de expandir el mercado a públicos distintos y satisfacer los requerimientos de una educación integral, los catálogos de la época se caracterizan por su amplitud temática y diversidad de géneros. Piénsese en la coexistencia de libros sobre teatro, cibernética, historia, política, literatura, etcétera, dentro de las distintas colecciones de Libros Cormorán, gran parte destinados a estudiantes. Es significativo también el hecho que Quimantú ofrece tres colecciones sobre literatura, pensada para distintos niveles de lectores, que incluyen géneros comerciales y obras políticamente comprometidas. Cabe mencionar que existe una apuesta por poner en valor las letras nacionales, en particular de la generación del 20 y del 38, valoradas por sus hondas impresiones de la realidad social. ${ }^{16}$

\footnotetext{
${ }^{16}$ En un texto recientemente publicado (Bascuñán, 2020), titulado Minilibros de Quimantú, un mundo entre la ficción Pulp y el realismo socialista, analizo el mundo literario desplegado en la colección Minilibros y refiero a la revalorización de la narrativa del 20 y 38 por parte de la editorial. Acerca de esto último sugiero revisar el prólogo que escribe Yerko Moretic (1962) para la antología El nuevo cuento realista chileno, publicada por Universitaria. Véase también a Jaime Concha (1973).
} 


\section{Puertas de la percepción}

Las portadas de las colecciones populares dan cuenta de diversos procesos de modernización técnica, disciplinar y estético-formal acontecidos en el campo de la gráfica.

A lo largo de los sesentas, gracias al desarrollo de la electrónica se producen cambios sustanciales en la industria gráfica chilena. Se sucedieron muchas innovaciones, como el perfeccionamiento de las prensas, el papel, las tintas, los tipos y la encuadernación, pero ningún cambio fue tan significativo como el paso de la "Tipografía al Offset", que menciona Soto-Veragua (2009), que ya era una realidad a comienzos de los setenta. La introducción del diccionario de letras transferibles Letraset fue uno de los componentes fundamentales en este proceso. Contribuyó a la superación definitiva del tipo del plomo -entiéndase la monotipia y linotipia- por procedimientos foto-mecánicos y foto-serigráficos, los cuales permitieron mayor libertad y precisión para componer.

Las transformaciones en el campo de la técnica se dieron en paralelo y sintonía con la profesionalización del diseño local. Signo de esto es el declive de la Escuela de Artes Aplicadas en 1968 y la apertura del Departamento de Diseño de la Universidad de Chile en su lugar. Se reconoce aquí una decidida orientación funcionalista, que se inclina hacia las técnicas industriales y un relativo distanciamiento con el arte. Significativas son las publicaciones de Mauricio Amster, tales como Técnica gráfica (1954, reeditado en 1966) o Normas de Composición (1969), acerca del uso de la tipografía, las tecnologías de impresión, composición y diagramación de libros. ${ }^{17}$

En el campo de la gráfica son asimilados $-\mathrm{y}$ transculturados- modernos referentes metropolitanos. A grandes rasgos hay dos grandes polos de influencia. Por un lado, se encuentran las influencias norteamericanas de la psicodelia y el pop, propias de una contracultura juvenil. Por otro, el Estilo Tipográfico Internacional, un exponente de las corrientes racionalistas de la Europa de post-guerra.

\footnotetext{
${ }^{17}$ Acerca del ocaso de la Escuela de Artes Aplicadas y de la apertura de la Escuela de Diseño de la Universidad de Chile véase a Castillo (ed.)(2010). Una panorámica general de las transformaciones dentro del campo del diseño en el periodo se encuentra en Álvarez (2004). Con respecto a la obra y figura de Amster, personalmente no recomiendo nada de lo que se ha escrito, ya que considero que que se abusa de la anécdota personal o se tratan temas demasiados específicos que no incitan a un diálogo amplio, no especializado.
} 
Desde mediados de los sesentas habrá una emergencia del arte pop en Chile. Es importante comprender esto más allá de un mero problema formal. Trata de un cambio en las lógicas producción artística donde los y las creadores asimilan los lenguajes, soportes y formatos de la sociedad de consumo y la cultura de masas. Se apuesta por vulgarizar la obra de arte y trazarle un horizonte masivo y popular. A diferencia del fenómeno norteamericano, caracterizado por su tendencia kitsch con tufillo nihilista, en Latinoamérica las diferentes expresiones pop suelen estar marcadas por un profundo compromiso político. Guardan una estrecha afinidad con las nuevas formas críticas del realismo en el arte. ${ }^{18}$ (Figuras 5 y 6 )

Algo similar se puede decir del arte psicodélico. Surge en Estados Unidos como una "manifestación del alma" vinculada al uso de drogas alucinógenas. Es un componente relevante de un movimiento contracultural, ligado al hippismo y rock \& Roll, que representa las aspiraciones a una libertad sin límites y de nuevas formas de percepción, no necesariamente racionales. A diferencia de los norteamericanos y sus devaneos románticos y escapistas, en Latinoamérica la cuerpo social disciplinado, fuerte y saludable como instruido.

${ }^{18} \mathrm{Al}$ respecto de los movimientos pop en general véase a Ragué (1973). Acerca de los vínculos entre la contracultura, el pop y la psicodelia a nivel local, veáse a Vico (2019). 


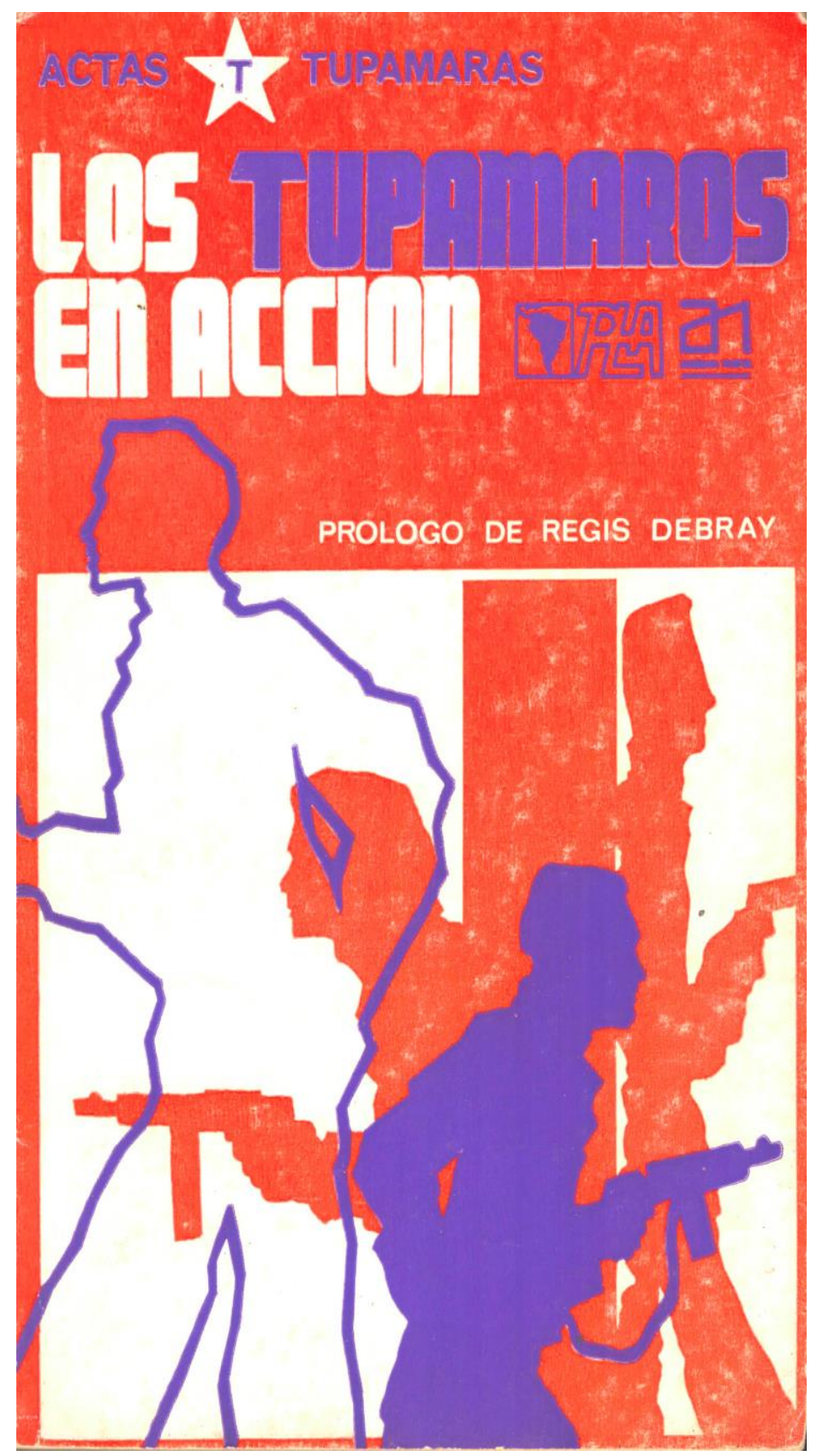

\section{Figura 5}

Los Tupamaros en acción editado por Prensa Latinoamericana, la editorial del Partido Socialista, en 1972. Llama la atención el empleo de un lenguaje pop, propio de la cultura de masas norteamericana, para referirse a la guerrilla urbana. Cabe mencionar que la tipografía del título es una variación de la Futura Display, perteneciente al diccionario Letraset, muy utilizada durante el periodo, tanto en libros, revistas y publicidad. Archivo personal. 


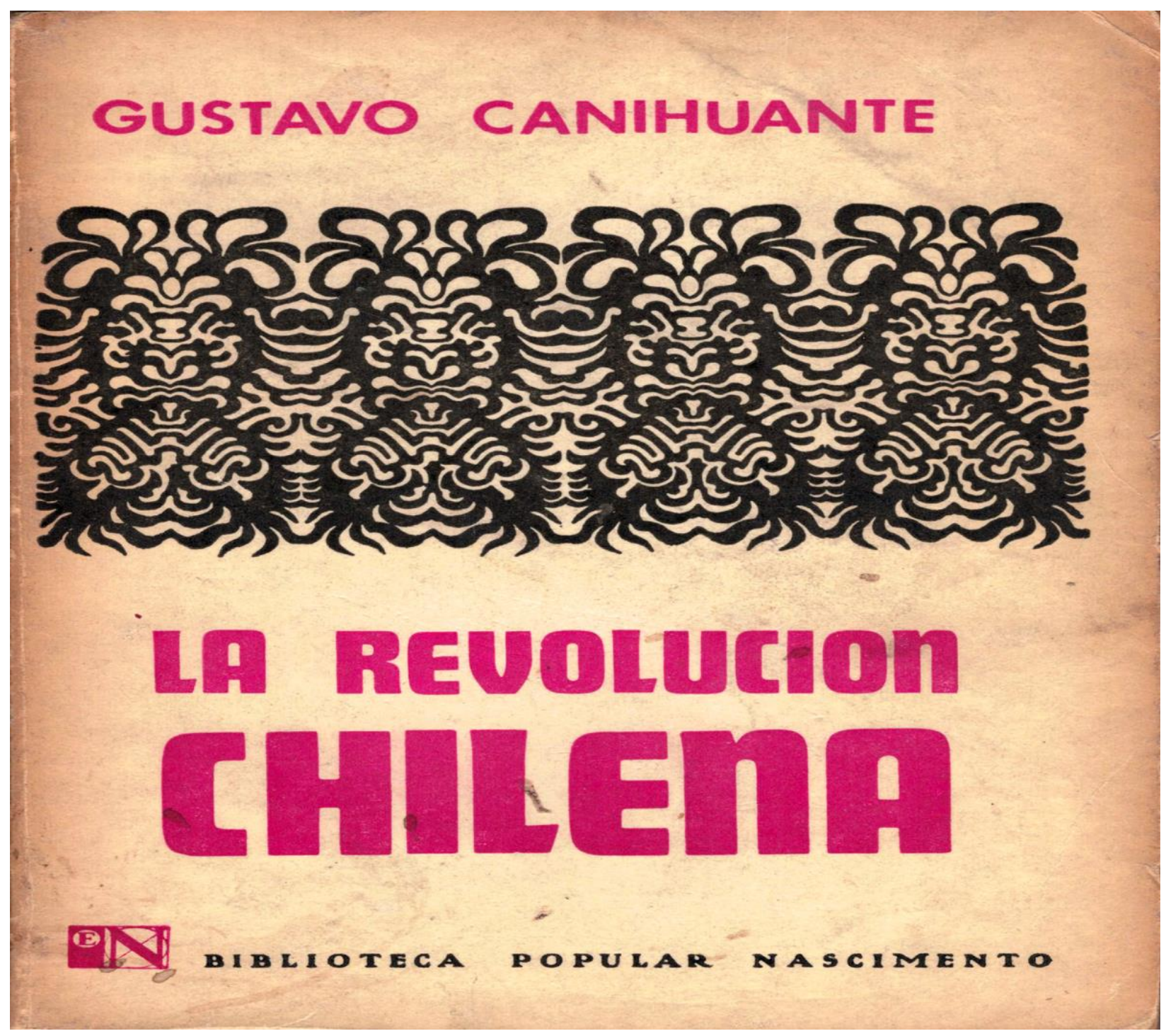

Figura 6

Publicado en 1971 por Editorial Nascimento.

La ornamentación está basada en ejercicio de recortes de papel realizados por Ludwig Zeller. El artista realizó cientos de estas composiciones en 1967, de las cuales varias fueron expuestas en la exposición Arte LSD. En relación con la tipografía, nótese que se trata de otro título compuesto con Futura Display. 


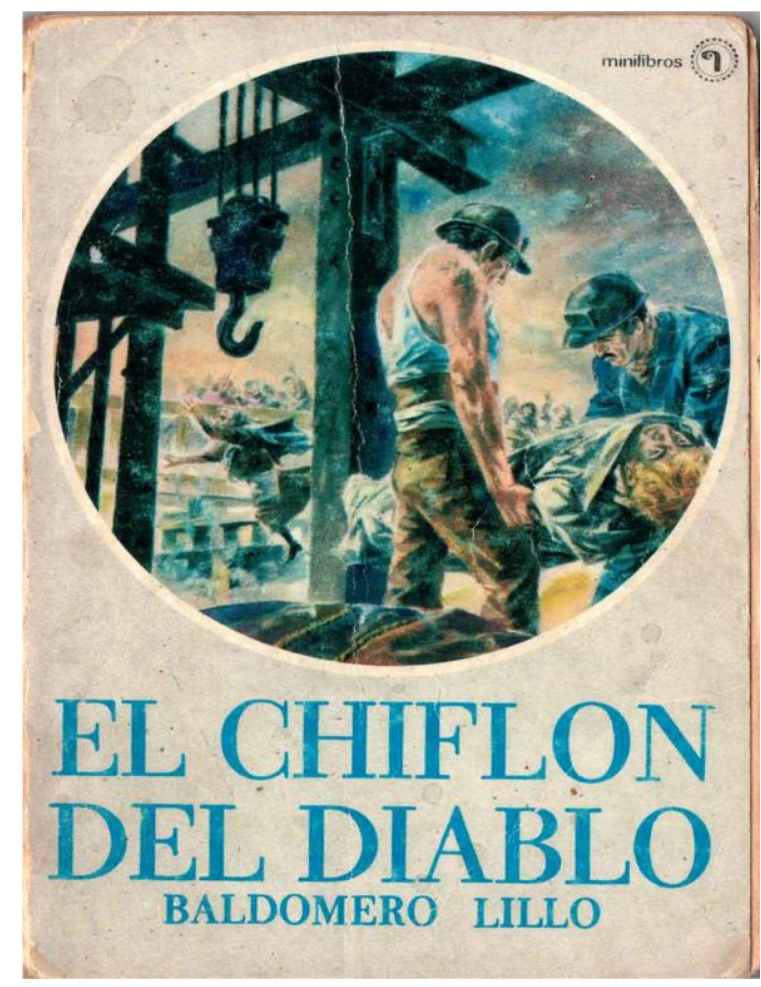

Figura 7

Publicado en agosto de 1972 con un tiraje de 50.000 copias. La portada es de Julio Berríos. Baldomero Lillo se considera "El padre del realismo social chileno", "el gran iniciador", como consigna la presentación del Minilibro.En la portada se emplea emula un lenguaje propio de la Literatura Pulp, característico de ciertos magazines y paperbacks norteamericanos que reúnen elementos de los cuentos de aventura, ciencia ficción, novela negra y novela rosa. De ahí proviene el término Pulp Fiction que emplea Tarantino. En el caso de Minilibros este lenguaje visual se emplea para retratar guerrilleros, mujeres proletarias y vigorosos mineros del carbón que encarnan los ideales del realismo socialista.

Relevante es como estas formas se conjugaron con el Estilo Tipográfico Internacional, también llamado Estilo Suizo. Se trata de la antítesis, en términos éticos y formales, de la anécdota pop y la embriaguez psicodélica. Surge en el periodo de post-guerra, obediente al mandato científico y de la mano de las aspiraciones de un resurgir democrático, ajeno a cualquier forma de nacionalismo. Se caracteriza por su 
voluntad de objetividad y racionalidad de las formas. Algunas de sus elementos distintivos son el uso de tipografías de palo seco o sin remates -presentes en los diccionarios Letraset-, grillas modulares y las

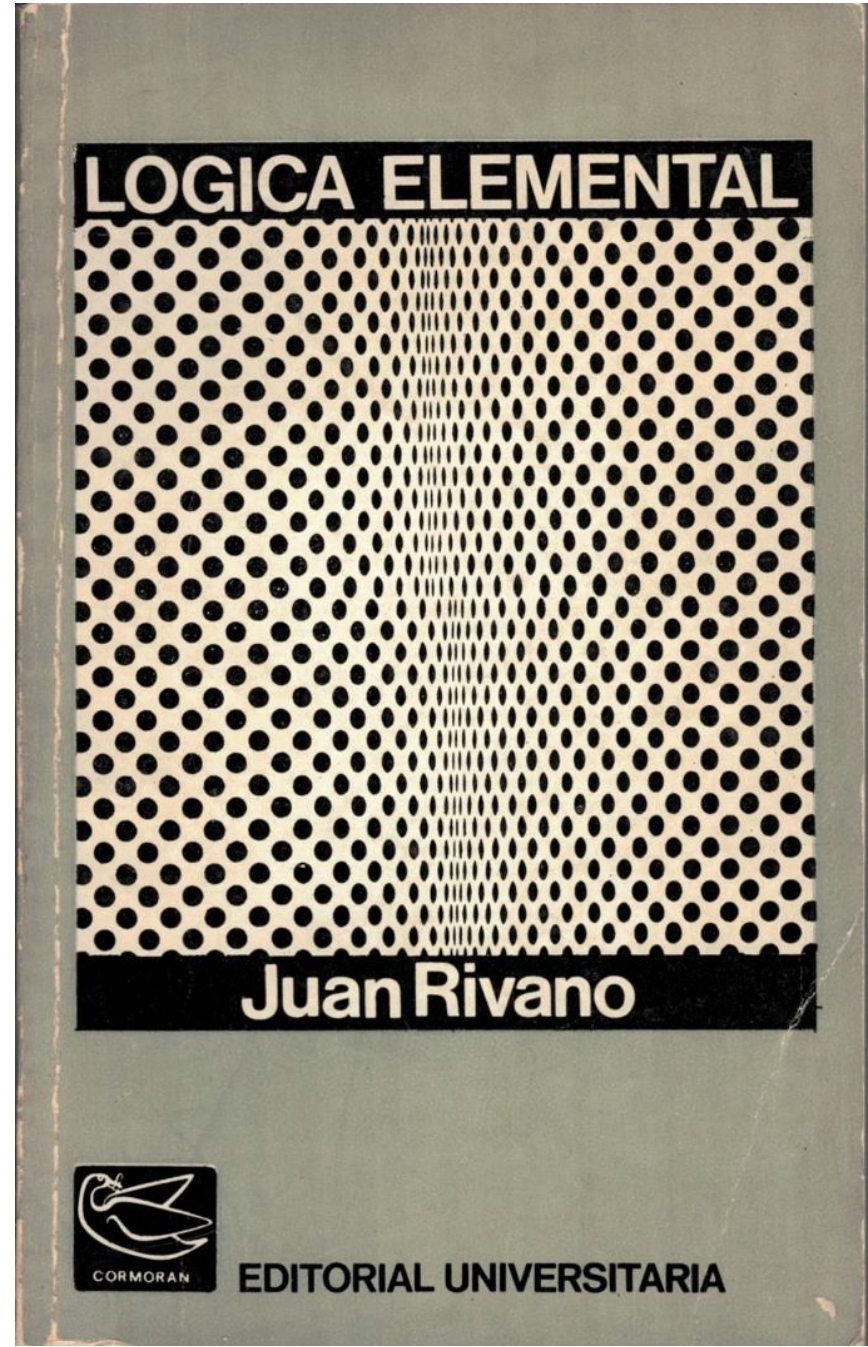

Figura 8

Libro publicado en 1970 para la colección Libros para el estudiante, perteneciente al sello Libros Cormorán. El diseño de la portada es Nelson Leiva y los interiores estuvieron a cargo de Mauricio Amster.

Cabe mencionar que Juan Rivano fue un destacado filósofo que impartió clases en la Universidad de Chile y de Concepción. Hegeliano y materialista, no es casualidad que su obra sea presentado con una obra de arte óptico y un diseño funcionalista, carente de simbolismo. 
derivas del arte concreto y del arte cinético. (Figura 8 y 9).

Interesa aquí dar cuenta que la acaecido en el campo de la gráfica no es ajeno a las tensiones de otros campos de la creación, en torno a los encuentros entre cultura masas y pensamiento ilustrado. Según los públicos y el tipo de obras, son diversas las opciones formales que se emplean. En definitivas cuentas, se trata de conjugar la racionalidad con el estímulo a los sentidos. Las puertas a la ciudad letrada son a la vez puertas de la percepción.

Es importante comprender que las innovaciones dentro del campo de la gráfica hacen posible la revolución del libro a nivel local. Hablamos de un momento donde es preciso hacer atractivo y competitivo al libro frente a otros medios, en tanto los soportes audiovisuales y los avances tecnológicos trazan nuevas xpectativas y horizontes en torno a la imagen. Es tremendamente significativo que durante periodo los libros lucen igual o más llamativos que los afiches de películas o magazines.

A modo de cierre, me gustaría enfatizar que lo aquí expuesto busca reconstruir las maneras determinadas en que la edición y la lectura se desarrollaron durante la Unidad Popular. Más que un análisis de casos he pretendido acercarme a las tensiones y lógicas tras la producción artística e intelectual. A mi entender, tensiones sin resolver y lógicas aún vigentes. 


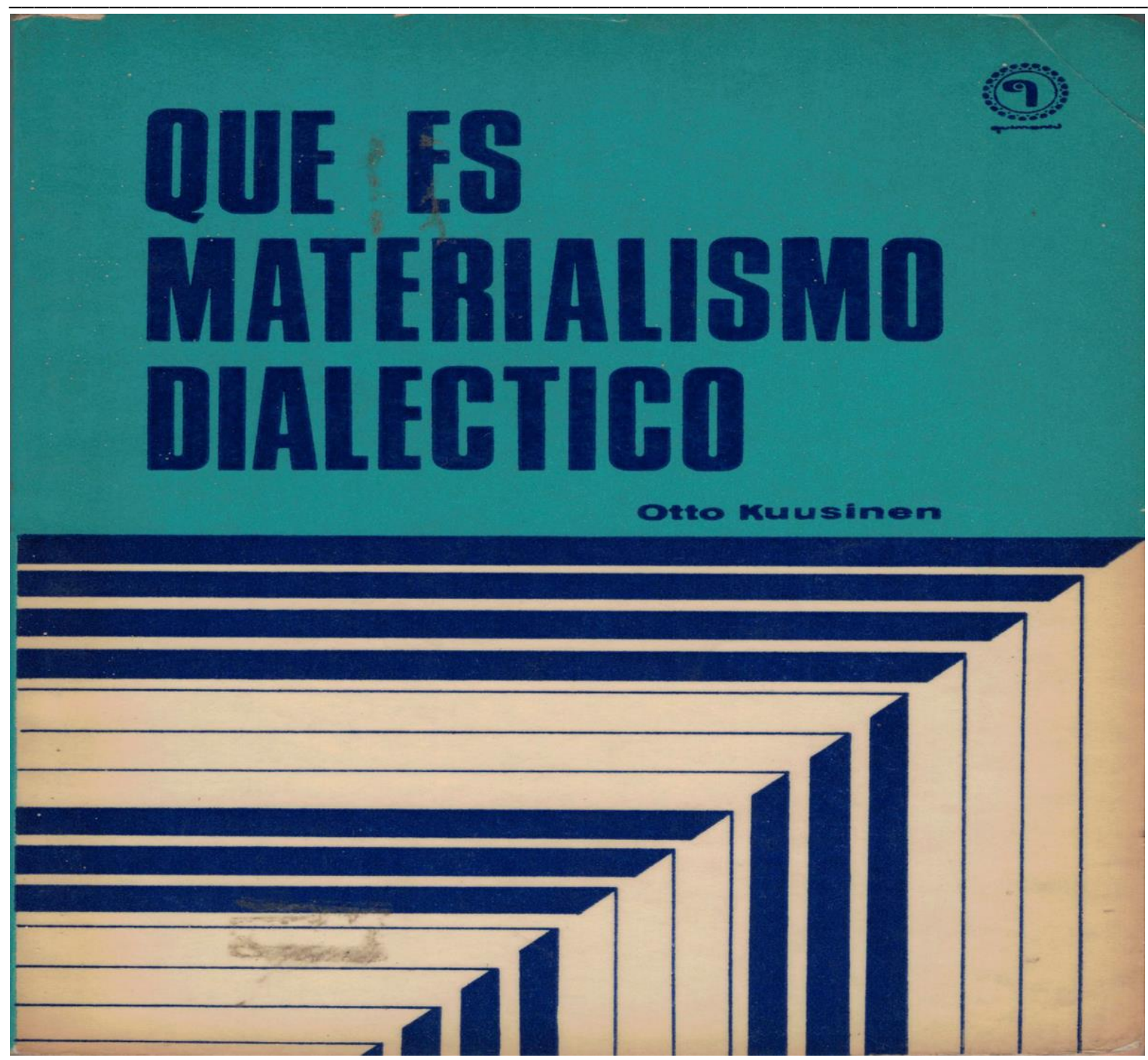

Figura 9

El arte concreto o concretismo es una corriente del arte abstracto que se origina en la década de los treinta en el seno de las vanguardias, muy influido ante todo por la experiencia neoplasticista. Es una tendencia que tendrá mucha resonancia en Latinoamérica, sobre todo en el Cono Sur, tanto en el arte pictórico como en la poesía visual. Dentro del campo del diseño se entroncará con las corrientes funcionalistas.

El arte concreto se distingue de otras formas de arte abstracto en la medida que niega toda figuración y relación con una naturaleza exterior a la obra artística. En este sentido fija su atención en los elementos concretos de la composición. En esto guarda una estrecha afinidad con las corrientes materialistas en el campo de la filosofía y el pensamiento, en la medida que la atención recae en las relaciones materiales por sobre cualquier expresión de idealismo.

Portada María Angélica Pizarra, 1972. 
Referencias bibliográficas

Albornoz, C. (2005), "La Cultura en la Unidad Popular. Porque esta vez no se trata de cambiar un presidente". En Pinto, Julio (Ed.), Cuando hicimos historia. La experiencia de la Unidad Popular (pp.147-175). LOM.

Álvarez, P. (2004). Historia del diseño gráfico en Chile. Ocho Libros.

Bascuñán, P. (2020). Minilibros de Quimantú: un mundo entre la literatura pulp y el realismo socialista. Meridional. Revista Chilena de Estudios Latinoamericanos, (15), 127-163. https://meridional.uchile.cl/index.php/MRD/article/view/58632/62872

Bascuñán, P. (2020b). Las puertas de Susana Wald (1967-1970) Alguha Revista de Cultura, (160). https://arcagulharevistadecultura.blogspot.com/2020/10/patricio-andres-bascunan-correa-las.html

Bergot, S. (2004). Quimantú: editorial del Estado durante la Unidad Popular Chile (1970-1973). Pensamiento Crítico, (4). https://docplayer.es/7103394-N-4-noviembre-2004-quimantu-editorialdel-estado-durante-la-unidad-popular-chilena-1970-1973-solene-bergot.html

Candina, A. (2012). La frágil clase media. URedes.

Casali, A. (2011) Reforma Universitaria en Chile, 1967-1973. Pre-balance histórico de una experiencia frustrada. Intus-Legere Historia, http://intushistoria.uai.cl/index.php/intushistoria/article/download/83/75.

Concha, J. (1973). Novelistas Chilenos. Quimantú.

Escarpit, R. (1965). La revolución del libro. Alianza Editorial.

Espinoza, C. (2015). El tren popular de la cultura [DVD]. Chile / España: Sociedad Sonora. Disponible en: https://canal.uned.es/video/5a6f2841b1111fc8588b4601

Facuse, M. (2018). Arte, cultura y política en la experiencia editorial de Quimantú. En Molina, I., Facuse, M., Facuse, I. Quimantú: prácticas, política y memoria (pp. 89-120). Grafito Ediciones.

Garretón, M. (2011). Universidad y política en los procesos de transformación en Chile 1967-1973. En Pensamiento Universitario 14(14), pp. 71-90. http://www.manuelantoniogarreton.cl/documentos/2012/mag2012universidades_y_politica.pdf

Harnecker, M. (1969). Los conceptos elementales del materialismo histórico. Siglo XXI. Huirimilla-Thiznau, A., Arros-Aravena, H. y Molina, R. (2019). Entre Valparaíso y Marilyn Monroe. Una reflexión sobre la creación de una editorial universitaria. Revista 180(43), 55-65. http://dx.doi.org/10.32995/rev180.Num-43.(2019).art-588

Mattelart, A. (1972). Agresión en el espacio. Tercer Mundo. 
Moretic, Y., Orellana, C. (1962). El nuеvo cuento realista chileno. Editorial Universitaria. Ragué, M. (1973). Los movimientos pop. Salvat Ediciones.

Rama, A. (1984). Más allá del boom: Literatura y mercado. Folios Ediciones.

Reyes, F. (2013). Nascimento. El editor de los chilenos. Minimocomún ediciones.

Ossandon y Santa Cruz (2005). El estallido de las formas: Chile en los albores de la "cultura de masas. LOM Ediciones / Arcis.

Saferstein, E. (2013). Entre los estudios sobre el libro y la edición: el giro material en la historia intelectual y la sociología. Información, Cultura y Sociedad, (29), pp.139-166.

https://www.redalyc.org/pdf/2630/263030849007.pdf

Soto Veragua, J. (2009). Historia de la imprenta en Chile. Árbol Azul, 2009.

Subercaseaux, B. (1984). La industria editorial y el libro en Chile (1930-1984). CENECA. http://www.memoriachilena.gob.cl/archivos2/pdfs/MC0036996.pdf

Subercaseaux, B. (1993). Historia del Libro en Chile. Lom Editores.

Subercaseaux, B. (2008). Editoriales y círculos intelectuales en Chile 1930-1950. Revista Chilena de Literatura, (72), pp. 221 - 233. http://repositorio.uchile.cl/bitstream/handle/2250/122810/Subercaseaux_Bernardo.pdf?sequence= $\underline{1}$

Sunkel, G. (1985). Razón y pasión en la prensa popular. Instituto Latinoamericano de Estudios Transnacionales.

Vico, M. (2013). El Estilo Tipográfico Internacional, su llegada a Chile. Revista de Diseño, (3), pp. 81100.

https://revistaidiem.uchile.cl/index.php/RChDCP/article/view/42664/44659

Vico, M. (2019). Todos juntos: iconografía de la contracultura en Chile. Fulgor. 